\title{
Energy and pressure requirements for compression of swine solid fraction compost
}

\author{
Niccolò Pampuro, Alessio Facello, Eugenio Cavallo \\ Istituto per le Macchine Agricole e Movimento Terra (IMAMOTER), Consiglio Nazionale delle \\ Ricerche (CNR), Torino (TO), Italy
}

\begin{abstract}
The excessive amount of pig slurry spread on soil has contributed to nitrate water pollution both in surface and in ground waters, especially in areas classified as vulnerable zones to nitrate in accordance with European Regulation (91/676/CEE). Several techniques have been developed to manage livestock slurries as cheaply and conveniently as possible and to reduce potential risks of environmental pollution. Among these techniques, solid-liquid separation of slurry is a common practice in Italy. The liquid fraction can be used for irrigation and the solid fraction, after aerobic stabilization, produces an organic compost rich in humic substances. However, compost derived from swine solid fraction is a low density material (bulk density less than $500 \mathrm{~kg} \mathrm{~m}^{-3}$ ). This makes it costly to transport composted swine solid fraction from production sites to areas where it could be effectively utilized for value-added applications such as in soil fertilization. Densification is one possible way to enhance the storage and transportation of the compost. This study therefore investigates the effect of pressure (20$110 \mathrm{MPa}$ ) and pressure application time (5-120 s) on the compaction characteristics of compost derived from swine solid fraction. Two different types of material have been used: composted swine solid fraction derived from mechanical separation and compost obtained by mixing the first material with wood chips. Results obtained showed that both the pressure applied and the pressure application time sig-
\end{abstract}

Correspondence: Niccolò Pampuro, Istituto per le Macchine Agricole e Movimento Terra (IMAMOTER), Consiglio Nazionale delle Ricerche (CNR), Strada delle Cacce, 73,10135 Torino (T0), Italy.

Tel. +39.011.3977723 - Fax: +39.011.3489218.

E-mail: n.pampuro@ima.to.cnr.it

Key words: density, specific energy, densification, swine manure.

Acknowledgements: This work was carried out within the framework of the "FITRAREF" project, funded by the Italian Ministry of Agriculture and Forestry (Call OIGA, 2009), under the scientific direction of Dr. Eugenio Cavallo (CNRIMAMOTER). The authors also wish to thank Mr. Giuseppe Paletto and Mr. Guarino Benvegnù (CNR-IMAMOTER) for the technical support.

() Copyright N. Pampuro et al., 2013

Licensee PAGEPress, Italy

Journal of Agricultural Engineering 2013; XLIV(s2):e105

doi:10.4081/jae.2013.s2.e105

This article is distributed under the terms of the Creative Commons Attribution Noncommercial License (by-nc 3.0) which permits any noncommercial use, distribution, and reproduction in any medium, provided the original author(s) and source are credited. nificantly affect the density of the compacted samples; while the specific compression energy is significantly affected only by the pressure. Best predictor equations were developed to predict compact density and the specific compression energy required by the densification process. The specific compression energy values based on the results from this study (6-32 $\left.\mathrm{kJ} \mathrm{kg}^{-1}\right)$ were significantly lower than the specific energy required to manufacture pellets from biomass feedstock (typically $19-90 \mathrm{~kJ} \mathrm{~kg}^{-1}$ ).

\section{Introduction}

The excessive amount of pig slurry spread on soil has contributed to nitrate water pollution both in surface and in ground waters, especially in areas classified as vulnerable zones to nitrate in accordance with European Regulation (91/676/CEE).

In order to avoid environmental pollution several technologies have been recently developed. Among these techniques, solid-liquid separation of slurry is a common practice in Italy. It leads to a solid fraction rich in phosphorous and organic matter, and to a liquid fraction which is rich in soluble nitrogen (Fangueiro et al., 2012). The liquid fraction can be used in land application or reused on the farm as flushing water (Garcia et al., 2009) and the solid fraction can be composted directly and/or co-composted with vegetable residues.

However, compost derived from swine solid fraction is a low density material (bulk density less than $500 \mathrm{~kg} \mathrm{~m}^{-3}$ - Pampuro et al., 2012). This makes it costly to transport composted swine solid fraction from production sites to areas where it could be effectively utilized for value-added applications such as in soil fertilization. Densification is one possible way to enhance the storage and transportation of the composted swine solid fraction.

Traditionally, agricultural materials are densified into pellets, cubes and bales. Pellets are the densest of these agglomerates. Therefore, they require the highest amount of input energy (19-90 $\left.\mathrm{kJ}^{\mathrm{kg}}{ }^{-1}\right)$ during manufacturing (Tabil and Sokhansanj, 1996). The manufacture of cubes uses lower pressure than pelletizing. Production of cubes is largely limited to forage crops such as alfalfa (Bernhart et al., 2010). Baling is a process that combines compression and packing operations. It is typically used for grassy or fibrous-like materials that are stringy in nature (Bernhart et al., 2010). Compost derived from swine solid fraction is not stringy and therefore not suitable for baling.

The overall goal of this study was to investigate the densification process of compost derived from swine solid fraction for efficient transportation and off-site utilization. The first specific objective of this research was to determine the specific energy requirement for compression of compost derived from swine solid fraction at different pressure and at different pressure application time. A second specific objective was to study the equations able to predict compact density and the specific compaction energy required to manufacture compacts from two composts derived from swine solid fraction. 


\section{Materials and methods}

\section{Sample preparation}

The tests were carried out using two different types of compost: swine solid fraction compost (SSFC) and wood chips compost (WCC). SSFC was obtained composting $6,000 \mathrm{~kg}$ of swine solid fraction, while WCC resulted by mixing $8,000 \mathrm{~kg}$ of swine solid fraction with $2,400 \mathrm{~kg}$ of wood chips obtained processing residues from park maintenance.

The initial bulk density of SSFC and WCC were 240 and $480 \mathrm{~kg} \cdot \mathrm{m}^{-3}$, respectively.

The initial moisture content of SSFC and WCC were 51.1 and $49.6 \%$ (wb), respectively. The moisture content of the samples (mass of $10 \mathrm{~kg}$ for each compost type) was reduced to $10 \%$ by drying in an oven set to $50^{\circ} \mathrm{C}$ (Bernhart and Fasina, 2009). Only one moisture level of $10 \%$ (wb) was used and this was based upon literature review that at this moisture level, high density and quality pellets/briquettes were produced from various straw and biomass (Li and Liu, 2000; Obernberger and Thek, 2004; Mani et al., 2006; Adapa et al., 2009).

\section{Compression equipment}

The press used to obtain the compressed material has two opposite hydraulic cylinders. The unit, fitted with an oil-hydraulic unit, can deliver up to $297 \mathrm{kN}$ in a time variable from 0 to 210 seconds. The press can be equipped with different compressing chambers as needed. In order to obtain the tests samples, a chamber with a diameter of $45 \mathrm{~mm}$ and a volume of $440 \mathrm{~cm}^{3}$ was used.

Upper and lower cylinders are fitted with load cells (max rated load $200 \mathrm{kN}$ ) that give signals proportional to the compressing force. The top of the plunger is connected with a potentiometric displacement sensor ( $350 \mathrm{~mm}$ full stroke) giving the exact position and volume of the compressing chamber. The oil feed line has a pressure transducer. These signals are processed by a pc-based acquisition system capable of acquiring up to $10 \mathrm{ks} / \mathrm{s}$. For this application the sampling rate was fixed to $1 \mathrm{ks} / \mathrm{s}$. All the collected data were recorded with a dedicated software for post-processing operations.

\section{Compression tests and energy calculations}

The mass of samples used for making compacts was $55.00 \mathrm{~g}$. Four preset pressures of 20,50,80 and $110 \mathrm{MPa}$ corresponding to loads of $31.5,62.3,126.1$ and $173.4 \mathrm{kN}$, were used to compress samples in the chamber. Five applications times $(5,10,40,90$ and $120 \mathrm{~s})$ for each pressure level were applied during densification process. For each material every combination of pressure and time was carried out with five replications (Figure 1).
A digital caliper was used to measure the length and the diameter, while a digital balance accurate to $0.01 \mathrm{~g}$ was used to measure the mass of densified material. The densities of the samples were calculated from the ratio of mass to volume.

During the compression of individual compacts, force-displacement data were recorded. Specific compression energy (SCE) was calculated following the methodology of Adapa et al. (2006) and Mani et al. (2006). The area under the force-displacement curve was integrated using the trapezoid rule (Santamarta et al., 2012); when combined with the briquette mass, it yielded the specific energy values in $\mathrm{kJ}^{\mathrm{kg}}{ }^{-1}$.

\section{Data analysis}

Regression analysis was performed using the proc reg function in SPSS statistical software package (Version 17.0) and plotted with the experimental data using Microsoft Excel (Microsoft Office 2007). Significance testing was carried out using one way analysis of variance (ANOVA) in the SPSS statistical package.

\section{Results}

\section{Compact density}

The pressure application time in the compression process has a highly significant effect on the density as well as the maximum applied pressure $(p<0.05)$. The interaction between the two parameters is not significant $(p>0.05)$.

For WCC the increase in density was significant $(p<0.05)$ for an increase of pressure application time from 10 to $40 \mathrm{~s}$ and from 90 to 120 $s$. For SSFC the increase in density was significant $(p<0.05)$ for an increase of pressure application time from 5 to $10 \mathrm{~s}, 10$ to $40 \mathrm{~s}$ and from 40 to $90 \mathrm{~s}$.

Results from the experiments showed that average density values ranged from 1,001 to $1,435 \mathrm{~kg} \cdot \mathrm{m}^{-3}$ and from 843 to $1,259 \mathrm{~kg} \cdot \mathrm{m}^{-3}$ for WCC and SSFC respectively, upon application of pressure in the range of 20 $110 \mathrm{MPa}$ (Table 1).

For each pressure level applied, WCC showed density values significantly $(p<0.05)$ higher than SSFC.

Eq. (1 and 2) were fitted to the experimental density values as a function of pressure application time and pressure for WCC and SSFC, respectively.

\begin{tabular}{|c|c|}
\hline pcompact $=179+0.5 * \mathrm{t}+260.1 * \ln (\mathrm{p})$ & $\mathrm{R}^{2}=0.996$ \\
\hline $\begin{array}{l}5 \mathrm{~s} \leq \mathrm{t} \leq 120 \mathrm{~s} ; 20 \mathrm{MPa} \leq \mathrm{p} \leq 110 \mathrm{MPa} \\
\text { pcompact }=52+0.93 * \mathrm{t}+247^{*} \ln (\mathrm{p}) \\
5 \mathrm{~s} \leq \mathrm{t} \leq 120 \mathrm{~s} ; 20 \mathrm{MPa} \leq \mathrm{p} \leq 110 \mathrm{MPa}\end{array}$ & $\mathrm{R}^{2}=0.995$ \\
\hline
\end{tabular}

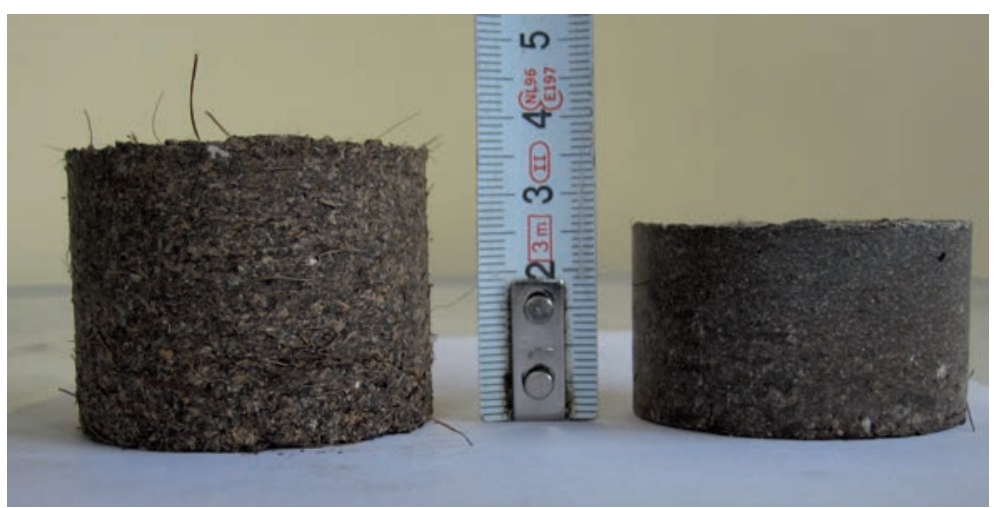

Figure 1. Samples obtained applying $50 \mathrm{MPa}$ for $40 \mathrm{~s}$ (SSFC on the left and WCC on the right). 


\section{Specific compression energy requirement}

The ANOVA showed no significant ( $p>0.05$ ) effect of pressure application time on specific compression energy consumption.

For applied pressures of 20,50, 80 and $110 \mathrm{MPa}$ the average specific compression energy required to form the briquettes was equal to 5.6, 12.7, 19.2 and $24.9 \mathrm{~kJ}^{\mathrm{kg}}{ }^{-1}$ for WCC and 9.0, 17.9, 25.4 and $32.2 \mathrm{~kJ}^{\mathrm{kg}} \mathrm{kg}^{-1}$ for SSFC.

For each pressure level applied, WCC showed specific compression energy values significantly $(p<0.05)$ lower than SSFC. This could be due to the effect of the composting process that leads to a weakening of the wood fires, compared to the swine manure, causing different energy adsorption.

For both materials there is a linear relationship between pressure and specific compression energy following the equation 3 (WCC) and 4 (SSFC).
$\mathrm{SCE}_{\mathrm{WCC}}=0.2124 * \mathrm{p}+1.666$
$\mathrm{R}^{2}=0.980$
$20 \mathrm{MPa} \leq \mathrm{p} \leq 120 \mathrm{MPa}$
$\mathrm{SCE}_{\mathrm{SSFC}}=0.254 * \mathrm{p}+4.694$
$\mathrm{R}^{2}=0.962$
$\mathrm{Eq}(4)$

$20 \mathrm{MPa} \leq \mathrm{p} \leq 120 \mathrm{Mpa}$

Figure 2 shows the relationship between specific compression energy and density of the densified samples.

For each density value obtained, SSFC showed specific compression energy values significantly $(p<0.05)$ higher than WCC (Table 2$)$.

For WCC and SSFC there is a non linear relationship between pcompact and SCE that can be explained with a exponential equation reported as follow.

$\mathrm{SCE}_{\mathrm{WCC}}=0.186 \mathrm{e}^{0.0034 \cdot \text { pcompact }}$

$$
\mathrm{R}^{2}=0.987
$$

$950 \mathrm{~kg} \cdot \mathrm{m}^{-3} \leq$ pcompact $\leq 1450 \mathrm{~kg} \cdot \mathrm{m}^{-3}$

$\mathrm{SCE}_{\mathrm{SSFC}}=0.735 \mathrm{e}^{0.0030 \cdot \text { pcompact }}$

$\mathrm{R}^{2}=0.956$

$\mathrm{Eq}(6)$
Table 1. Average density values (kg.m-3) of WCC and SSFC materials obtained using different pressure levels $(20,50,80$ and $110 \mathrm{MPa})$

\begin{tabular}{lcc}
$\begin{array}{l}\text { Applied pressure } \\
(\mathrm{MPa})\end{array}$ & \multicolumn{2}{c}{ Materials } \\
20 & $1,001 \pm 35$ & $843 \pm 37$ \\
50 & $1,218 \pm 30$ & $1,078 \pm 41$ \\
\hline 80 & $1,344 \pm 32$ & $1,170 \pm 32$ \\
110 & $1,435 \pm 25$ & $1,259 \pm 35$ \\
\hline
\end{tabular}

Table 2. Average density and specific compression energy values of WCC and SSFC materials obtained using different pressure levels $(20,50,80$ and $110 \mathrm{MPa}$ )

\begin{tabular}{|c|c|c|c|}
\hline \multicolumn{2}{|c|}{ WCC } & \multicolumn{2}{|c|}{ SSFC } \\
\hline peompact $\left(\mathrm{kg} \cdot \mathrm{m}^{-3}\right)$ & SCE (kJ.kg-1) & pcompact $\left(\mathrm{kg} \cdot \mathrm{m}^{-3}\right)$ & SCE (kJ.kg-1) \\
\hline $1,001 \pm 34$ & $5.6 \pm 0.4$ & $843 \pm 37$ & $9.0 \pm 0.7$ \\
\hline $1,218 \pm 30$ & $12.7 \pm 0.6$ & $1,078 \pm 41$ & $17.9 \pm 0.7$ \\
\hline $1,344 \pm 32$ & $19.2 \pm 1.1$ & $1,170 \pm 32$ & $25.4 \pm 1.1$ \\
\hline $1,435 \pm 25$ & $24.9 \pm 1.7$ & $1,259 \pm 35$ & $32.2 \pm 0.9$ \\
\hline
\end{tabular}

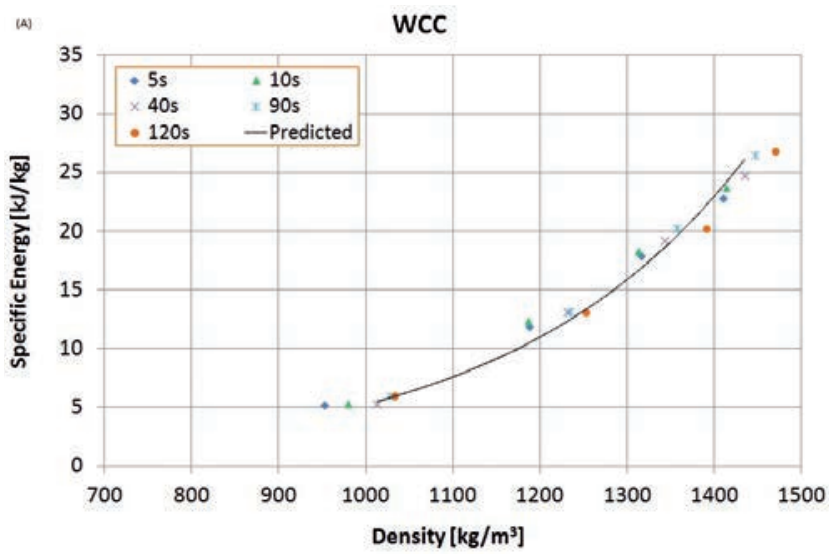

Previous studies conducted by Demirbas (1999) have shown a logarithmic relationship between applied pressure and resulting density of briquettes manufactured from waste paper and wheat straw mixtures and applied pressure. Even though considerably higher pressures were used in that study (300-800 MPa), the briquette densities obtained (50$850 \mathrm{~kg} \cdot \mathrm{m}^{-3}$ ) were lower than the densities obtained in this study. We suspect this is due to the different properties of the materials under test.

Adapa et al. (2009) during pellettization of different types of straw, found a polynomial relationship between applied pressure and resulting density. The mean densities of barley, canola, oat and wheat straw compacts increased from 907 to $988 \mathrm{~kg} \cdot \mathrm{m}^{-3}, 823$ to $1003 \mathrm{~kg} \cdot \mathrm{m}^{-3}, 849$ to $1011 \mathrm{~kg} \cdot \mathrm{m}^{-3}$ and 813 to $924 \mathrm{~kg} \cdot \mathrm{m}^{-3}$, respectively, upon application of pressure in the range of 31.6-138.9 MPa. Although, the moisture level of $10 \%$ (wb) used by Adapa et al. (2009) was equal to the moisture content used in this study, we have obtained higher density values applying pressure levels of 20-110 MPa. This could be due to the different characteristics of the densification process investigated.

The specific compaction energy values found in this study were considerably higher than those found by Bernhart et al. (2010) during the compaction tests of poultry litter. The two main reasons for this difference were that the densities reached by Bernhart et al. (2010) were much lower than the densities found for this work and the moisture content of poultry litter was substantially higher.

The specific compression energies calculated for the densification of compost derived from swine solid fraction were lower than the values found by Santamarta et al. (2012). Using a moisture content of $10.76 \%$

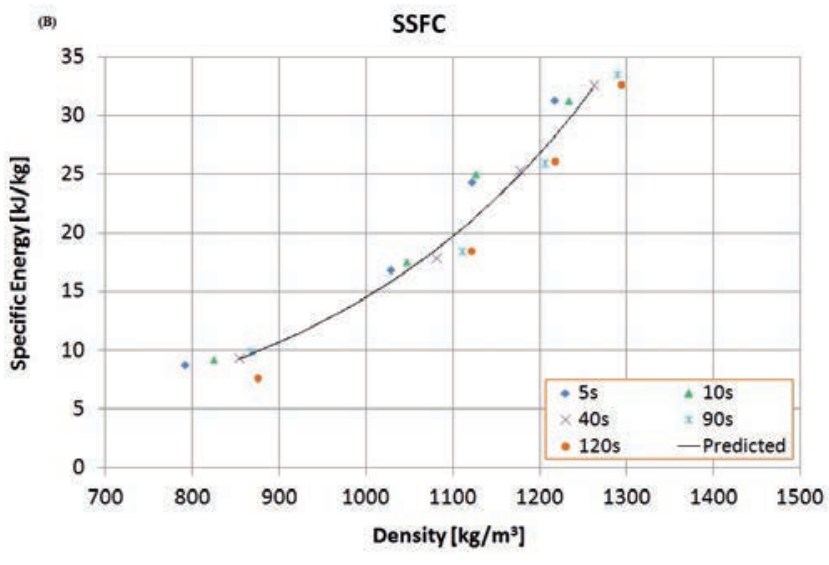

Figure 2. Relationship between specific compression energy and density to form the WCC (A) and SSFC (B) briquettes. 
and an applied pressure of $47.7 \mathrm{MPa}$, the specific energy required to form the OSR straw briquettes was $24.95 \mathrm{~kJ}^{\mathrm{kg}}{ }^{-1}$, compared to 12.7 and 17.9 $\mathrm{kJ}^{\mathrm{kg}}{ }^{-1}$ used to produce WCC and SSFC briquettes, respectively, when the applied pressure was $50.0 \mathrm{MPa}$ and the moisture content was $10 \%$.

Moreover the average specific compression energy values found with this trial were lower than the specific energy required to manufacture pellets from biomass feedstock (typically $19-90 \mathrm{~kJ}^{\mathrm{kg}} \mathrm{kg}^{-1}$; Colley et al., 2006).

As stated by Mani et al. (2004), the energy requirements depend mainly upon the applied pressure and moisture content, but also on the physical properties of the material and the method of compaction.

It can be concluded that the pressure agglomeration process is more efficient than the pellettization process - the specific energy values obtained were significantly lower and the final density values were higher when applying the same compaction pressure level.

The results from this study could be used in the design of economical and simple on-farm pressure agglomeration equipment.

\section{References}

Adapa PK, Schoenau GJ, Tabil LG, Sokhansanj S, Singh A, 2006. Compression of fractionated sun-cured and dehydrated alfalfa chops into cubes - specific energy models. Bioresource Technol 98: 38-45.

Adapa P, Tabil L, Schoenau G, 2009. Compaction characteristics of barley, canola, oat and wheat straw. Biosyst Eng 204: 335-344.

Bernhart M, Fasina 00, 2009. Moisture effect on the storage, handling and flow properties of poultry litter. Waste Manage 29: 1392-1398.

Bernhart M, Fasina 00, Fulton F, Wood CW, 2010. Compaction of poultry litter. Bioresource Technol 101: 234-238.

Colley Z, Fasina 00, Bransby D, Lee YY, 2006. Moisture effect on the physical characteristics of switch grass pellets. T ASABE 49: 18451851.

Demirbass A, 1999. Physical properties of briquettes from waste paper and straw mixture. Energy Convers Manage 40: 437-445.

Fangueiro D, Lopes C, Surgy S, Vasconcelos E, 2012. Effect of the pig slurry separation techniques on the characteristics and potential availability of $\mathrm{N}$ to plants in the resulting liquid and solid fractions. Biosyst Eng 113: 187-194.

Garcia MC, Szogi AA, Vanotti MB, Chastain JP, Millner PD, 2009. Enhanced solid-liquid separation of dairy manure with natural flocculants. Bioresource Technol 100: 5417-5423.

Li Y, Liu H, 2000. High-pressure densification of wood residues to form an upgraded fuel. Biomass Bioenerg 19: 177-186.

Mani S, Tabil LG, Sokhansanj S, 2004. Evaluation of compaction equations applied to four biomass species. Canadian Biosystems Eng 46: 351-361.

Mani S, Tabil LG, Sokhansanj S, 2006. Specific energy requirement for compacting corn stover. Bioresource Technol 30: 648-654.

Obernberger I, Thek G, 2004. Physical characterization and chemical composition of densified biomass fuels with regard to their combustion behavior. Biomass Bioenerg 27: 653-669.

Pampuro N, Facello A, Cavallo E, 2012. Density-pressure relationship in densification of swine solid fraction. Proc International Conference of Agricultural Engineering, Valencia (Spain), July 812.

Santamarta LC, Ramirez AD, Godwin RJ, White DR, Chaney K, Humphries AC, 2012. Energy use and Carbon Dioxide emissions associated with the compression of oilseed rape straw. Proc International Conference of Agricultural Engineering, Valencia (Spain), July 8-12.

Tabil LG, Sokhansanj S, 1996. Process conditions affecting the physical quality of alfalfa pellets. Appl Eng Agric 12: 345-350. 